\title{
Exosome signaling: A ubiquitous process in rejection and regeneration?
}

\author{
Igor E. Konstantinov, MD, PhD, FRACS, and Matthew S. Yong, MBBS
}

\footnotetext{
From the Department of Cardiac Surgery, Royal Children's Hospital, Melbourne, Victoria, Australia; Department of Paediatrics, University of Melbourne, Melbourne, Victoria, Australia; and Murdoch Children's Research Institute, Melbourne, Victoria, Australia.

Disclosures: Authors have nothing to disclose with regard to commercial support.

Received for publication Jan 10, 2018; accepted for publication Jan 12, 2018; available ahead of print Feb 23, 2018 .

Address for reprints: Igor E. Konstantinov, MD, PhD, FRACS, University of Melbourne, Royal Children's Hospital, Flemington Rd, Parkville, Victoria 3029, Australia (E-mail: igor.konstantinov@ rch.org.au).

J Thorac Cardiovasc Surg 2018;155:2490-1

$0022-5223 / \$ 36.00$

Crown Copyright (c) 2018 Published by Elsevier Inc. on behalf of The American Association for Thoracic Surgery https://doi.org/10.1016/j.jtcvs.2018.01.021
}

Endomyocardial biopsy remains a gold standard for surveillance of cellular rejection after heart transplantation. A noninvasive blood test that can accurately predict rejection would be of great benefit and may result in a paradigm shift in clinical monitoring of rejection. Gene expression-profiling assays of RNA and quantification of circulation donor-derived cell-free DNA have been studies for noninvasive monitoring of rejection. ${ }^{1-4}$ Although assessment of nucleic acids alone is promising and may lead to noninvasive clinical prediction of rejection, those tests have not yet replaced endomyocardial biopsy.

A fascinating article by Habertheuer and colleagues ${ }^{5}$ is published in this issue of the Journal. In their elegant and insightful study, the authors demonstrated that quantification of donor-specific exosomes in peripheral blood can detect an early rejection with high accuracy in a murine heterotopic heart transplantation model. The authors found that donor heart releases a distinct pool of major histocompatibility complex specific exosomes into the recipient circulation. In acute rejection, there was an increase in donor-specific exosome levels that correlated well with each grade of cardiac allograft rejection. This study highlights the ubiquitous processes underpinning exosome signaling.

Exosomes are bilayered membrane-bound nanoparticles $\left(30-100 \mathrm{~nm}\right.$ ) (Figure 1) ${ }^{6,7}$ that are derived from the luminal membrane of the multivesicular body and released by fusion of the membrane of multivesicular body with the cell surface membrane. Multiple cell types, including stem cells, endothelial cells, myocardial cells, and neuronal cells, secrete exosomes. ${ }^{6,7}$ Exosomes have tissue-specific surface receptor profiles and can mediate intercellular communication by transfer of proteins, transcription factors, lipids, messenger RNAs, and microRNAs. ${ }^{7}$ These products can

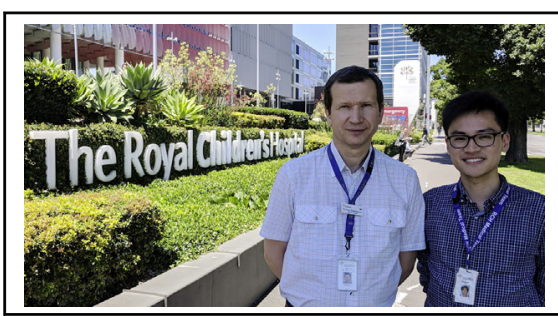

Igor E. Konstantinov, MD, PhD, FRACS, and Matthew S. Yong, MBBS

\section{Central Message}

Exosome signaling is a phenomenon of intercellular communication. Quantification of exosomes may become a novel technique for noninvasive detection of rejection after heart transplantation.

See Article page 2479. then induce differential gene expression in the target cells and result in myocardial remodeling. ${ }^{8}$ This common signaling process may be central to myocardial response to any injury caused by infection, inflammation, ischemia, or rejection. For instance, in myocardial remodeling (Figure 1), after an ischemia-reperfusion injury, microRNA is altered and released from the injured myocardium and carried locally and to distant organs via exosomes. ${ }^{6,9}$ Cardiac exosomes are believed to then reprogram the bone marrow to release progenitor cells and induce myocardial repair ${ }^{6}$ or, in species with lost ability to regenerate, remodeling of the myocardium by hypertrophy and fibrosis. ${ }^{10}$ Similar process may occur in heart transplantation. During rejection and injury to transplanted heart, donor-specific exosomes are released into the recipient circulation. Therefore, quantification of exosomes with a donor-specific major histocompatibility complex or intra-exosomal contents forms the basis of transplant rejection monitoring. ${ }^{5,11}$ Although the role of exosomes in transplantation has not yet been clearly identified, it appears that exosome signaling may play a key role in rejection. Understanding the ubiquitous process of exosome signaling may open new prospects in the diagnosis and management of the whole spectrum of cardiovascular disease from myocardial regeneration to rejection of a transplanted heart. 


\section{Transplantation}
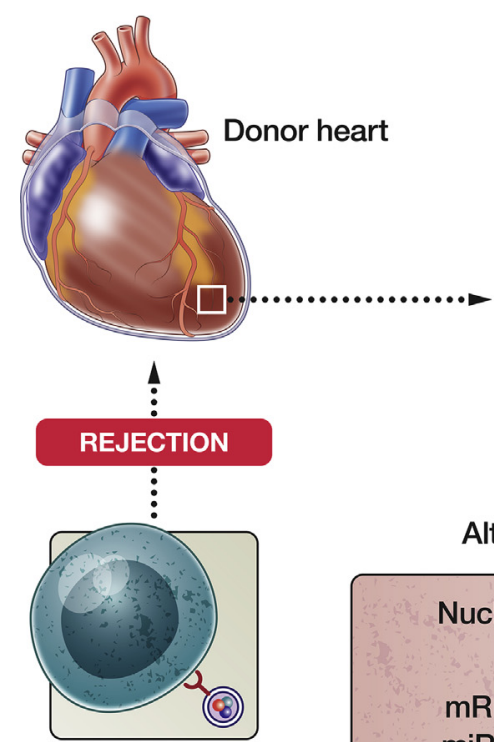

T-cell priming

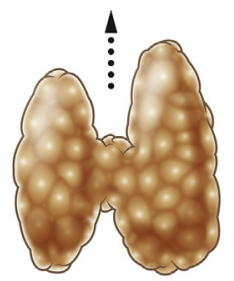

Thymus and lymphatic system

$\vdots$

\section{Ischemia-Reperfusion Injury}
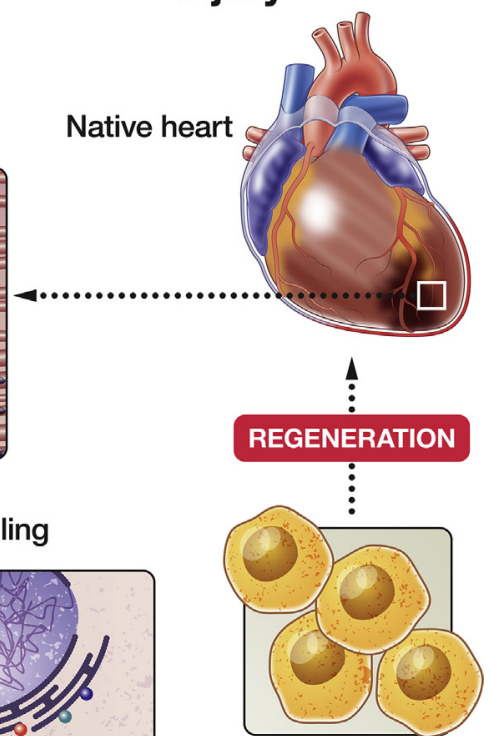

Progenitor cell migration

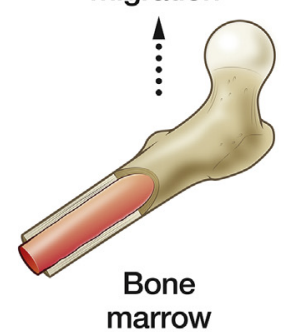

Blood stream

FIGURE 1. Exosome signaling is a phenomenon that plays a key role in intercellular communication. Exosomes are nanovesicles that are released from cells by exocytosis. In myocardial injury, the organ-specific surface receptors of the cell membrane, including major histocompatibility complex, are internalized into a multivesicular body. The exosome formation by inward budding of the cell membrane ensures that the membrane-bound receptors preserve the same orientation on the exosomal membrane as those on the plasma membrane. The exosomes are filled with nucleic acids and proteins from the endoplasmic reticulum and Golgi complex and are released into the bloodstream. The exosomes induce mobilization of progenitor cells in the bone marrow and their migration into the myocardium to induce regeneration or, in species with lost ability to regenerate, remodeling of the myocardium. In myocardial rejection after heart transplantation, the donor heart releases a distinct pool of donor major histocompatibility complex-specific exosomes into the recipient circulation that results in T-cell priming in the lymphatic system of the recipient. MHC, Major histocompatibility complex; $M V B$, multivesicular body.

\section{References}

1. Xin A, Lee MGY, Hu Y, Ignjatovic V, Shi WY, Shipp A, et al. Identifying low-grade cellular rejection after heart transplantation in children using gene expression profiling. Physiol Genomics. December 20, 2017 [Epub ahead of print].

2. Pham MX, Teuteberg JJ, Kfoury AG, Starling RC, Deng MC, Cappola TP, et al. Gene-expression profiling for rejection surveillance after cardiac transplantation. N Engl J Med. 2010;362:1890-900.

3. De Vlaminck I, Valantine HA, Snyder TM, Strehl C, Cohen G, Luikart H, et al. Circulating cell-free DNA enables noninvasive diagnosis of heart transplant rejection. Sci Transl Med. 2014;6:241ra77.

4. Snyder TM, Khush KK, Valantine HA, Quake SR. Universal noninvasive detection of solid organ transplant rejection. Proc Natl Acad Sci U S A. 2011;108: 6229-34.

5. Habertheuer A, Korutla L, Rostami S, Reddy S, Lal P, Naji A, et al. Donor tissue specific exosome profiling enables noninvasive monitoring of acute rejection in mouse allogeneic heart transplantation model. J Thorac Cardiovasc Surg. 2018;155 2479-89.

6. Sahoo S, Losordo DW. Exosomes and cardiac repair after myocardial infarction. Circ Res. 2014;114:333-44

7. Thery C, Zitvogel L, Amigorena S. Exosomes: composition, biogenesis and function. Nat Rev Immunol. 2002;2:569-79.

8. Waldenstrom A, Ronquist G. Role of exosomes in myocardial remodeling. Circ Res. 2014;114:315-24.

9. Ailawadi S, Wang X, Gu H, Fan GC. Pathologic function and therapeutic potential of exosomes in cardiovascular disease. Biochim Biophys Acta. 2015;1852:1-11.

10. Konstantinov IE, Ye XT, Fricke TA. From cellular senescence to regeneration: a quest for the holy grail for the next generation of surgeons? J Thorac Cardiovasc Surg. 2017;154:953-4.

11. Vallabhajosyula P, Korutla L, Habertheuer A, Yu M, Rostami S, Yuan CX, et al. Tissue-specific exosome biomarkers for noninvasively monitoring immunologic rejection of transplanted tissue. J Clin Invest. 2017;127:1375-91. 